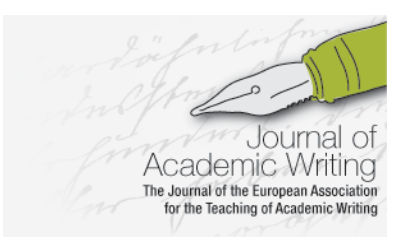

Journal of Academic Writing

Vol. 10 No 1 WINTER 2020, pages 128-135 https://doi.org/10.18552/joaw.v10i1.604

\title{
Talking about Writing - Designing and Establishing Writing Feedback and Tutorials to Promote Student Engagement and Learning
}

\author{
Fia Christina Börjeson \\ Chalmers University of Technology, Sweden \\ Carl Johan Carlsson \\ Chalmers University of Technology, Sweden
}

\begin{abstract}
This article describes different feedback designs that have been developed at Chalmers University of Technology, Sweden. These feedback activities are part of courses and programmes that faculty at the Department of Communication and Learning in Science, Division for Language and Communication, are involved in. The feedback setup has evolved from many years of designing and delivering writing instruction within STEM education, grounded in the challenge to make feedback a meaningful learning experience for all students and improve students' understanding of disciplinary academic writing. The feedback designs described are based on dialogue to provide feedback and as a means for students to verbalize their own understanding of text, textual features and how discipline specific content is communicated. Examples of setups are large class active feedback lectures, scaffolded peer response sessions, and guided feedback workshops. These feedback activities are explored, and we argue for how they, potentially, result in more (useful) feedback and feedforward compared to traditional written teacher-student feedback.
\end{abstract}

\section{Introduction}

The academic literacies that students need to internalize to become active participants within academia, include both general and discipline specific aspects (Lea \& Street, 2006). A crucial part of academic literacy is writing, as writing in higher education is shaped, on the one hand, by common academic principles, and on the other hand, by epistemological traditions and discourses. Therefore, it is crucial that the students actively engage with these types of writing. It is also important that learning activities are scaffolded and that students receive timely feedback in a format they can implement in their progression as writers at the university (Nicol \& MacFarlane-Dick, 2006; Weaver, 2006).

While feedback on students' writing is something most agree on as being important, a complicating factor is often that the number of students at universities is growing and thereby increasing the workload for teachers. Therefore, ways of addressing this increasing workload become more and more important for many teachers, and the issue of scaling is something that has guided some of the pedagogical designs for feedback described in this article.

In our case, writing instruction is based on the academic literacies approach (Lea \& Street, $1998,2006)$ and has been designed to promote both disciplinary learning and disciplinary socialization by adopting a WID (Writing in the Disciplines) approach with writing instruction taking place across the curriculum and across campus (Gustafsson et al., 2011). This means that writing activities are integrated in content courses in the different engineering and science programmes. Therefore, academic and technical writing is taught within the disciplinary 
contexts, and the writing tasks include learning both the disciplinary content and disciplinary writing (e.g. Paretti et al., 2019). Since writing instruction is integrated, writing is situated and students engage with genres and text types that are specific for their discipline.

An important aspect of the integrated writing activities in the content courses and projects, which this article is based on, is that the texts the students produce are read by both communication teachers and content teachers. This dual readership puts focus on content and on how students should communicate content within their discipline. So, at the same time as genre expectations, format and language are aspects the students need to address, writing is also an important tool for understanding, shaping and formulating disciplinary knowledge. The concept of writing to learn (e.g. Carter, Ferzli, \& Wiebe, 2007) is thereby an important focus in our teaching practice and something that we want to make our students aware of.

\section{Designing feedback for student learning}

Feedback for promoting student learning is a fundamental aspect of writing pedagogy today, and there are many didactic approaches that address this in different ways (e.g. Boud \& Molloy, 2013; Juwah et al., 2004; Nicol \& MacFarlane-Dick, 2006). Common among them is the focus on the student and the student's needs, and that feedback must be relevant and understood by the student (e.g. Lea \& Street, 1998; Weaver, 2006). In line with this view, we aim to make our feedback and assessment practices both learner and learning oriented by using formative feedback processes, during the writing process as well as when assessing the end product.

Known problems with written feedback is that the students do not understand the feedback (Sommers, 2012) or that the feedback is just seen as proofreading for the students to correct (Weaver, 2006). In both these situations, feedback is separated from learning (Arts et al., 2016). With an approach where students and teachers are involved in a dialogue about feedback, these problems can be mitigated (Carless, 2016; van der Schaaf et al., 2013).

In our feedback, we primarily focus on the role of writing, the specificities of disciplinary writing, genre awareness, organization, and conceptual understanding and argumentation in an academic setting. Of course, this does not mean that there are no proficiency issues or that these are not addressed. However, the main focus of the writing instruction and feedback is on the construction and communication of knowledge within the specific academic and disciplinary settings. In order for this feedback to be efficient, the feedback sessions are supported by writing lectures and workshops, forming an integrated sequence of writing instruction within the different disciplinary courses.

With a focus on different aspects of academic literacy, we are able to design feedback that is more genre-based and content-oriented in that the comments the students get are intended to support their discourse awareness and disciplinary socialization. In the following sections, we describe three feedback setups designed to support student learning.

\section{Large class feedback lectures}

Giving feedback in the form of a lecture originates from the challenge to teach writing to large classes which, in our case, means between 100 to more than 250 students. The feedback lectures are based on the particular assignment in the respective courses and focuses on the type of comments we want to make the students aware of.

Before the lecture, the students have received written feedback on their texts. We try to refrain from writing fully explanatory comments and instead use underlining, yellow-marked sections and abbreviated comments. As the comments are sparse in each report, all comments and areas that we want to lift in the texts are therefore discussed during the feedback lecture. This way, the time spent on reading, commenting, and expanding on the comments, can be quite significantly reduced for each text, especially for longer texts such as reports in capstone project courses. 
This means that we go through the feedback in class while the students have their own text in front of them, helping them interpret the feedback they have received in their texts. Going through the feedback during a specifically devoted lecture also means that, apart from expanding on the comments, examples can be shown and discussed, providing much more detailed and comprehensive feedback that would be difficult and time-consuming to include in regular written feedback comments.

An important part of the pedagogical design of the lectures is that students are actively engaged in the feedback by discussing and comparing the feedback with their peers. The lectures therefore include activities that allow students to share comments, discuss problematic issues and propose solutions in class. Also, as part of each lecture, the students are given the time and opportunity to discuss the feedback and ask questions in order to get further explanations or advice from the teachers.

Since the feedback is given in two steps (first the short comments or highlighting in the text, and then the verbal and visual feedback in the lecture), students are given some time to process and reflect on the feedback before asking for advice from the teachers.

\section{Guided feedback workshops}

With a similar setup as the feedback lectures, the guided feedback workshops are designed for smaller classes. The workshops are designed for feedback on individually written texts or texts written in pairs or groups. The classes normally vary between 20 to 40 students.

As with the feedback lectures, the workshop starts with a comprehensive briefing where we go through the types of comments and instances that we have highlighted in the texts. This is mainly done in thematic order, going through the different parts and functions of the texts and showing examples of ways of dealing with potentially problematic aspects. Again, the purpose is to be able to provide guided feedback to all students by discussing and proposing solutions to common issues that the students encounter in the different assignments.

To ensure student activity during the briefing, students are asked to discuss and to provide solutions to the issues that are brought up. Then, after the briefing, the students get their reports back with short comments and highlighted sections and spend the remaining time of the workshop editing their text based on the feedback. The teachers make sure to discuss any issues with the students to see that they have understood the feedback.

In the same way as in the large class feedback lectures, it is the actual texts that the students have produced that inform the teaching and learning activities, as opposed to having generic lectures on the text type in question. By being both appropriate in time (the students are engaged in a writing process) and in scope (each lecture or session is designed based on teachable aspects of what the students have produced), we aim to make feedback relevant and accessible to the students.

\section{Scaffolded peer response sessions}

As is common in many approaches to teaching writing in higher education, feedback from peers is an important learning activity. Our scaffolded peer response sessions are organized at different stages during the writing process and the scope of the sessions vary depending on the writing assignment and on where in the process it takes place.

Peer response sessions that are organized early in the writing process, tend to focus on discussions about the scope and direction of the text; helping the writers formulate research questions and a plan for the text. At later stages, the response is more directed to the actual text and how the text is perceived by a reader; testing the text and its content. For sessions in the early writing stages, peers often read the drafts in class, and for sessions where there is more substantial text, reading is done beforehand.

Regardless of whether the peer response session requires pre-reading or not, students are given guidelines to help them look for certain aspects or issues in the texts and how to give and receive feedback. This way, each session can have its specific focus and be directed to make 
the students aware of what learning objectives we want to achieve in the session and how this relates to the assessment criteria for the specific writing assignment. For instance, this can be related to anything from style and register, paragraphing and structure, to handling of content, terminology, or precision of arguments. In other words, our scaffolded peer response workshops can either be more focused on higher order concerns or on later order concerns, depending on timing.

The setup in the classroom also varies from students giving feedback one-to-one, to involving constellations of several peers giving each other response. What the sessions always have in common is that the feedback is dialogic (e.g. Bakhtin, 1981; Linell, 2009; Steen-Utheim \& Wittek, 2017). That is, the students discuss the texts and provide spoken feedback rather than handing over written feedback. Of course, often the students also hand over the commented text to each other, but the important feature of the sessions is that the reader and the writer together discuss and negotiate the feedback on the texts.

By letting the students engage in conversations about the texts, we want to encourage dialogic and self-directed learning strategies among the students. The intention with this setup is therefore to make the students aware of their role in shaping their own learning and understanding. An important affordance with these student conversations is that we encourage them to discuss content and content understanding. This way, students are focusing on the communicative aspects of the texts and how the subject matter is understood, providing opportunities for student-driven dialogues about learning and content understanding.

During the time that the students discuss their text and their feedback, the teacher listens to the different groups and collects questions or problematic aspects that come out of the discussions. Also, the students are asked to report back on the feedback they have given and received to see if there are any questions that can be clarified. At the end of the response session, there is a joint discussion where the teacher responds to questions and addresses issues that were brought up in the peer discussions.

\section{Preparing student centred in-class feedback}

When preparing the feedback lectures and workshops, we customize teachable examples by extracting problematic aspects as well as good examples from the students' own texts. Even if we mask and redesign the examples so that no students feel we are exposing their individual text, the feedback is more direct and potentially perceived as more relevant than if the feedback would have been more generic, such as textbook examples. This way, the students are guided through the feedback, focusing on specific instances that are important to address, and that the students easily can relate to. For instance, if frequent problems with data commentary, paragraphing, or academic register are found, we can discuss this and show clarifying examples from the students' texts in class.

Reading and collecting issues we want to address may seem time consuming, and to a certain extent it is. However, rather than providing (detailed) comments and feedback in each student text, the feedback is instead elaborated on in the lectures and workshops. This means that we refrain from detailed comments and explanations in the students' texts (which we admit can be hard to stick to...) and instead use shorthand notes, circling or highlighting issues in the texts. In essence, the written feedback is only there to point to certain issues that we bring up in class, rather than providing clarifying or explaining comments in each text.

The preparations for the scaffolded peer response sessions focus on providing prompts that the students can use when reading and giving feedback (no pre-reading for teachers). Together with an introduction to what a successful peer response session entails (e.g. such as an accepting environment and constructive feedback), the provided guidelines are designed to focus on particular aspects that we want the students to direct their attention to. 
The scaffolding guidelines for each peer response session are based on the specific learning outcomes we want to target, and on the assessment criteria for the assignment the students are working on. In this way, the students are made aware of the link between the expectations on their writing described in the learning outcomes and criteria, and how they actually meet those expectations.

Examples and guidelines that have been developed can to a large extent be used again the next time the feedback lecture, workshop, or peer response session is given. Therefore, time can be saved by collecting a bank of examples and areas that we want to make our students aware of. For instance, examples can include anything from common language mistakes and use of terminology, issues of style and academic register, to paragraphing and other structural issues. Of course, it is important that the examples and material reflect the actual occurrences of issues in the student texts, but many of the aspects are recurring in many writing assignments.

\section{Making feedback an opportunity to talk about writing}

Even though the feedback comments we provide have been minimized in order to save time and to handle large classes, the approaches with feedback lectures, guided feedback workshops, and scaffolded peer response sessions have been developed to be more student focused and learning oriented than "regular" written feedback.

Therefore, scaling is just a factor, but central to all three of these approaches to feedback is that we talk about the texts and about the feedback. In the feedback lectures and in the feedback workshops, the texts and the conventions of the particular genre or text type are discussed and exemplified in order to make the feedback as transparent and accessible as possible to the students. In the guided peer response sessions, students talk about, and negotiate, text, textual features, and expectations of texts within the disciplinary setting they find themselves in.

Another gain with in-class feedback is that students potentially can get feedforward on their next step in the writing process. For instance, in a feedback lecture we may discuss issues in a particular section of the text that we have seen in some students' work, but that some other students have not started on. So, in that respect students can also get feedback on parts of the text they have not written or finalized yet. In essence, they can get feedback on aspects they did not know that they did not know. Moreover, the feedback is also not only provided but also discussed in class which allows the students to get a broader and deeper response to their writing.

A familiar problem with feedback is that it tends to focus more on problems and shortcomings than on positive comments. This problem is apparent also in our setup as the highlighted areas in the students' texts often focus on text or structures that can be improved, even if we also put an effort into providing positive feedback. However, in the different feedback sessions, students also get verification of things they have done correctly simply by seeing that a specific feature we address in class is carried out correctly in their own text. That is, by hearing the multitude of issues and aspects brought up in the sessions, students also get indirect positive feedback on their writing. 


\section{Conclusion}

The way we have set up our feedback lectures and sessions, feedback becomes a "teachable moment" where what the students have actually produced becomes the source of information and is actively discussed in class. That is, instead of risking that the students either do not understand the feedback or that they actually ignore reading it (e.g. final assessment comments), we can focus our effort on transforming previously mostly written feedback into dialogues about text and writing. The intention is therefore to design feedback practices that promote active learning, self-directed learning and dialogically negotiated understanding. Therefore, all the feedback designs described here build on the fact that dialogue is important - both to explain the feedback and for students to verbalize their own understanding of text, textual features and discipline specific discourses.

In addition to discussions about texts, students also engage in discussions about the assignment, which helps them interpret requirements and expectations. The discussions inevitably also revolve around content. Moreover, the peer sessions often provide an appreciated opportunity for the students to actively engage in discussing and exploring the subject matter in a reciprocal manner. Not only does this motivate the students, it is also clear that the students utilize the peer response sessions as an opportunity for broader learning, expanding their knowledge about both subject, text, and genre.

Based on our experience, we see that it is possible to engage students as agents in the feedback process and to provide qualitative response to students' texts also in very large classes. Scaling and adapting feedback procedures to manage a great number of students does not mean that they get less feedback. Instead, by setting up feedback activities where we exemplify and discuss texts and feedback with our students, we can offer more feedback than what would have been feasible through traditional written-only feedback, while spending less time on giving feedback on each text. 


\section{References}

Arts, J. G., Jaspers, M., \& Joosten-ten Brinke, D. (2016). A case study on written comments as a form of feedback in teacher education: so much to gain. European Journal of Teacher Education, 39(2), 159-173. https://doi.org/10.1080/02619768.2015.1116513

Bakhtin, M. (1981). The dialogic imagination: four essays. University of Texas Press.

Boud, D., \& Molloy, E. (2013). Rethinking models of feedback for learning: The challenge of design. Assessment and Evaluation in Higher Education, 38(6), 698-712. https://doi.org/10.1080/02602938.2012.691462

Carless, D. (2016). Feedback as Dialogue. In M. A. Peters (Ed.), Encyclopedia of Educational Philosophy and Theory (pp. 1-6). https://doi.org/10.1007/978-981-287-532-7 389-1

Carter, M., Ferzli, M., \& Wiebe, E. N. (2007). Writing to Learn by Disciplines. Journal of Business and Technical Communication, 21(3), 278-302.

Gustafsson, M., Eriksson, A., Räisänen, C., Stenberg, A.-C., Jacobs, C., Wright, J., WyrleyBirch, B., \& Winberg, C. (2011). Collaborating for Content and Language Integrated Learning: The Situated Character of Faculty Collaboration and Student Learning. Across the Disciplines: A Journal of Language, Learning, and Academic Writing, 8(3).1-11.

Juwah, C., Macfarlane-Dick, D., Matthew, B., Nicol, D., Ross, D., \& Smith, B. (2004). Enhancing student learning through effective formative feedback. The Higher Education Academy (Generic Centre).

https://www.heacademy.ac.uk/sites/default/files/resources/id353 senlef guide.pdf

Lea, M. R., \& Street, B. V. (1998). Student Writing in Higher Education: An academic literacies approach. Studies in Higher Education, 23(2), 157-172.

https://doi.org/10.1080/03075079812331380364

Lea, M. R., \& Street, B. V. (2006). The “Academic Literacies" Model: Theory and Applications. Theory Into Practice, 45(4), 368-377.

Linell, P. (2009). Rethinking language, mind, and world dialogically: interactional and contextual theories of human sense-making. Information Age Pub.

Nicol, D., \& MacFarlane-Dick, D. (2006). Formative assessment and selfregulated learning: A model and seven principles of good feedback practice. Studies in Higher Education, 31(2), 199-218. https://doi.org/10.1080/03075070600572090

Paretti, M. C., Eriksson, A., \& Gustafsson, M. (2019). Faculty and Student Perceptions of the Impacts of Communication in the Disciplines (CID) on Students' Development as Engineers. IEEE Transactions on Professional Communication, 62(1), $27-42$. https://doi.org/10.1109/TPC.2019.2893393

Sommers, N. (2012). Beyond the red ink: students talk about teachers' comments. Bedford/St. Martin's.

Steen-Utheim, A., \& Wittek, A. L. (2017). Dialogic feedback and potentialities for student learning. Learning, Culture and Social Interaction, 15 (December 2016), 18-30. https://doi.org/10.1016/j.Icsi.2017.06.002

van der Schaaf, M., Baartman, L., Prins, F., Oosterbaan, A., \& Schaap, H. (2013). Feedback Dialogues That Stimulate Students' Reflective Thinking. Scandinavian Journal of Educational Research, 57(3), 227-245. https://doi.org/10.1080/00313831.2011.628693 
Weaver, M. R. (2006). Do students value feedback? Student perceptions of tutors' written responses. Assessment and Evaluation in Higher Education, 31(3), 379-394. https://doi.org/10.1080/02602930500353061 